\title{
Long Period Waves and Oscillations Over Costa Rica, a Tropical Station
}

\author{
M. Kanakadurga, P. Vinay Kumar, Salauddin Mohammad, Mohammed Yousuf, Gopa Dutta
}

\begin{abstract}
Seasonal, annual and interannual variations of Ozone Mixing Ratio (OMR) have been studied for 12 years, from balloonsondes and Ozonesondes that were launched over Costa Rica $\left(10^{\circ} \mathrm{N}, 83.4^{\circ} \mathrm{W}\right)$, a tropical station, as part of Southern Hemisphere Additional Ozonesondes (SHADOZ) network. It was found that near tropopause region there exists prominent peak of OMR during July month for most of the years. Lomb-Scargle Periodogram (LSP) analysis has been applied for the years 2005-2017 to identify the wave activities and found that Quasi Biennial Oscillations (QBO) with period of 2-2.5 years and even higher period oscillations of 3-4 years are prominent in middle troposphere and lower stratosphere regions which could cause large annual variabilities of OMR fluctuations. Fluctuations of OMR were subjected to Morlet wavelet transform over a year, 2008 , to study seasonal variabilities. The wavelet analysis confirm that Madden Julian Oscillations (MJO) with periods 49-60 days are prominent during summer near tropopuase and in lower stratosphere regions, while lower period equatorial Kelvin waves of 14-20 days periods dominate during winter and spring in troposphere region, which could be responsible for maximum seasonal variability.
\end{abstract}

Keywords: Ozone Mixing Ratio (OMR), Quasi Biennial Oscillation (QBO), Madden-Julian Oscillation (MJO), Kelvin waves

\section{INTRODUCTION}

Ozone is an important trace gas in the Earth's atmosphere. In stratosphere it shields the Earth's surface by absorbing harmful solar radiaton of 200-340 nm range. Ozone plays a major role in chemistry and climate of the troposphere and initiates cleansing of various pollutants, such as carbon monoxide, methane, among others, in the troposphere region of the atmopshere. However, its concentration increases due to man made activities, biomass burning, lightning incidents from ozone rich stratosphere. Hence, enhanced concentration

Revised Manuscript Received on April 25, 2020.

* Correspondence Author

M. Kanakadurga*, Assoc. Prof, Dept of H\&S, Vignana Bharathi Institute of Techology, Ghatkesar, Hyderabad - 501301, India. Email

Palla Vinay Kumar, Asst. Prof, Dept of H\&S, Aurora Technological Research Institute, Uppal, Hyderabad, India - 500098. Email:

Saluddin Mohammad, Post Doctoral Fellow, Academia Sinica, Taipei, Taiwan. Email: salauddin.physics@gmail.com

Mohammed Yousuf, Research Scholar, R\&D Center, Vignana Bharathi Institute of Technology, Ghatkesar, India - 501301.

Research Scholar, Dept of ECE, KL Deemed to be University, Vaddeswaram, Vijayawada - 522502 Email: yousufibnishaq@gmail.com

Gopa Dutta, Director R\&D, Vignana Bharathi Institute of Technology, Hyderabad, India. 501301. email:gopadutta@yahoo.com.

(C) The Authors. Published by Blue Eyes Intelligence Engineering and Sciences Publication (BEIESP). This is an open access article under the CC BY-NC-ND license (http://creativecommons.org/licenses/by-nc-nd/4.0/) of ozone in troposphere gives rise to greenhouse effect which influences ecosystem and agricultuture, etc. The ozone abundances in upper troposphere and lower stratosphre are mainly controlled by various chemical and dynamical processes such as photochemical production within the troposphere, downward and/or upward transport from the stratosphere or troposphere through stratosphere-troposhere exchange (STE) [1,2], transport processes within the troposphere [3] and deep convection [4]. Long term variations of ozone in troposphere and stratopshre reveal a complex pattern over the globe and in some cases are controlled by regional influences. The distribution of ozone in tropical regions is inhomogeneous with latitudinal and longitudinal gradients. Studies on ozone trends in tropical region reported decreasing trend of $3-8 \%$ per decade in the tropical lower stratosphere of 28 - $38 \mathrm{~km}$ with a peak around $32 \mathrm{~km}$, using Stratospheric Aerosol and Gas Experiment (SAGE-II) data during 1984-2005 and SHADOZ measurements during 1998-2009 [5,6]. Fadnavis, et al reported increasing trends of ozone 0.5 - $3.5 \%$ per year in the tropics in upper troposphere [6]. Seasonal variations of ozone and its interannual variability in upper troposphere have been studied by several researchers $[7,8,9,10]$. Stolarski et al reported from their studies that the seasonal cycle of ozone is stronger in the northern tropical lower stratosphere of northern hemisphere as compared to that in the southern tropical lower stratopshere of southern hemisphere, thus showing hemisheric differences in the seasonal variations of ozone [8]. The seasonal ozone variations over European high latitudes were studied by Rao et al and Wernel et al [11,12]. They found that just above the tropopause, there exist strong ozone variations over the observed period from 1994 to 2004 [12] and during 1994-2001 and 1991-2001 at two stations [11]. From their studies it was reported that a secondary ozone maximum appeared just above the tropopause for every year from late spring to summer with varying amplitude, in addition to ozone maximum in $17-20 \mathrm{~km}$ height region. This second maximum is shown to be related to temperature inversion layer [12]. Rao et al [11] found that interannual variability is maximum in lower stratosphere in winter and spring and mentioned that this could be related to wave driven stratospheric circulation. Schoeberl et al [13] studied seasonal differences in vertical structures in upper troposphere and lower stratosphere from balloonsonde profiles of water vapor and ozone at Costa Rica from 2005 to 2011. Their seasonal studies revealed that ozone profiles are lifted upward due to upward shifing of potential temperature surfaces during winter relative to summer. These seasonal differences of tracer variabilities were explained by three mechanisms, viz., wave variability, source variability and path variability.

Published By:

Blue Eyes Intelligence Engineering DOI: 10.35940/ijeat.D6483.049420

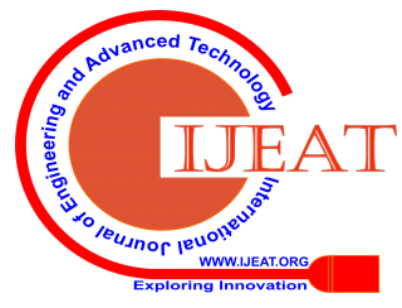


The vertical structure of water vapor and ozone soundings were made at Costa Rica during NASA Tropical Convective Systems and Processes (TCSP), Tropical Composition, Clouds, and Climate Coupling Experiment (TC4) campaigns [14] and at three closely located sites near Sanjose since 2005 as part of the Ticosonde project $[15,16]$. From their campaign data analysis at Costa Rica in July 2005 during TCSP mission and in July-August 2007 during TC4 mission, Selkirik et al [14] discussed the role of equatorial waves in temperature variations of tropical tropopause layer. The current study focusses on time series of seasonal variabilities, annual and interannual variations of ozone in troposphere and lower stratosphere and the role of wave activity that drives these variabilities, during the period from 2005 to 2017 at Costa Rica $\left(10^{\circ} \mathrm{N} 83.4^{\circ} \mathrm{W}\right)$ from measurements made by balloon borne ozonesondes launched once a week as a part of SHADOZ network. Description of data used in the present study is given in section 2 . Section 3 explains the detailed study of variation of OMR with time and the spectral analyses techniques that were carried out to identify the wave activities that are responsible for seasonal and annual variabilities. Section 4 summarizes the work with concluding remarks.

\section{DATA ANALYSIS}

SHADOZ is a project of NASA which was started in 1998 with other US and international co-investigators. Balloon-borne ozonosondes are launched regularly, once a week, from the stations in SHADOZ network.The vertical high resolution weekly data were archived from the SHADOZ website https://tropo.gsfe.nasa.gov/shadoz/archive.html and downloaded the data from 2005 to 2017 for a tropical station Costa Rica (10o N, 83.4o W). Ozone and temperature distributions were constructed as functions of height and time (weekly) for every year from 2005 to 2017. In the present work four seasons of a year have been defined as (i) winter December, January, February, (ii) spring - March, April, May, (iii) summer - June July, August, (iv) fall - September, October, November.

\section{RESULTS AND DISCUSSION}

Figure 1 shows the seasonal variation of monthly mean of OMR for years 2005 - 2017 at three selected heights, in troposphere, $12 \mathrm{~km}$ height, near tropopause, $16 \mathrm{~km}$ height and in lower stratosphere, $20 \mathrm{~km}$ height. In troposphere the overall peak appears during summer, July-August, for most of the years. However, the year 2012 shows peak values during Jan, March, June and October, every season almost in a periodic manner. The year 2006 shows two peaks in spring and fall, while year 2017 exhibits a single peak during summer. Near tropopause region at $16 \mathrm{~km}$ height, the seasonal variation of OMR throughout the year is shown in the figure 1 (b). The distribution of OMR over the year indicates that a prominent peak appears during summer, July month, for most of the years, as noted from the figure 1 (b). The year 2015 behaves in a slightly different manner with increased OMR values during summer and spring but appears a peak during fall season. Figure 1 (c) shows the seasonal variation of OMR in lower stratosphere at a height of $20 \mathrm{~km}$. The overall trend of OMR variation in a year shows higher ozone values during spring and summer for most of the years.
The time height cross section of OMR monthly mean of July (summer) for years 2005 - 2017 are shown in figure 2 in troposphere and in lower stratosphere regions. It can

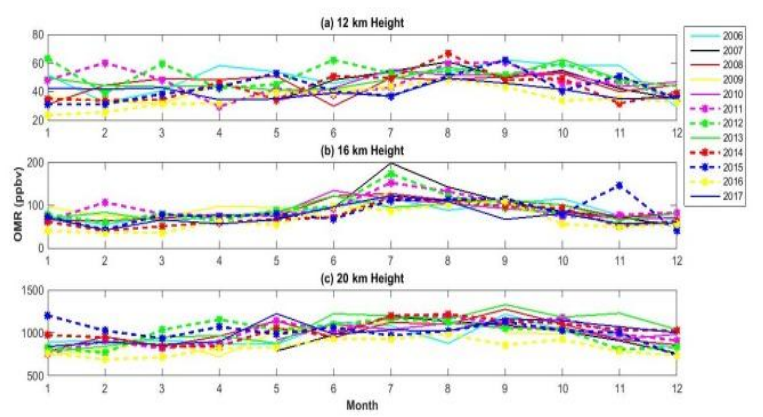

Figure 1 Mean monthly variations of OMR at (a) 12 km (b) $16 \mathrm{~km}$ (c) $20 \mathrm{~km}$ heights.

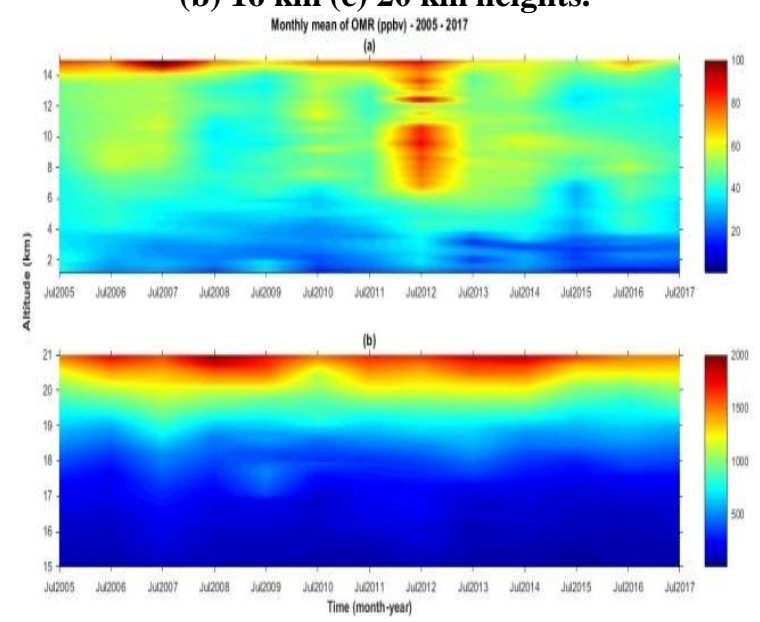

Figure 2 Time height cross section of OMR for monthly mean of July.

be observed from the diagram of figure 2 (a) that year 2012 exhibits higher intensity of OMR in lower heights of troposphere as compared to other years. In lower stratosphere and near tropopause region the interannual variability of OMR can be clearly seen from the figure 2 (b). The contour diagram reveals that OMR values exhibit oscillatory pattern near tropopause and in lower stratosphere below $20 \mathrm{~km}$ height, with period of approximately $2-3$ years. In the height region of above $20 \mathrm{~km}$, the annual oscillations of OMR indicate periodicity of 5 years as indicated from the figure 2 (b). Hence, it can be said that the annual undulations of OMR in tropopause and in lower stratosphere may be caused by atmospheric oscillations of QBO and higher periodic waves during summer season of July month. Figure 3 shows the OMR with July monthly mean of every year from 2005 to 2017 whch reveals wavy pattern at selected heights of $12 \mathrm{~km}$ and $16 \mathrm{~km}$, as indicated by the figure 3 . It can be seen from the figure that near tropopause region OMR exhibits more wiggles as compared to that in troposphere. In order to study the interannual variability, the spectral analyses of temperature and OMR have been done for the years 2005 2017 using least squares fit. Lomb-Scargle Periodogram (LSP), a popular method of spectral analysis

Published By:

Blue Eyes Intelligence Engineering \& Sciences Publication (C) Copyright: All rights reserved.

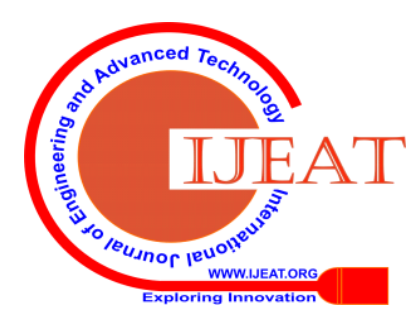




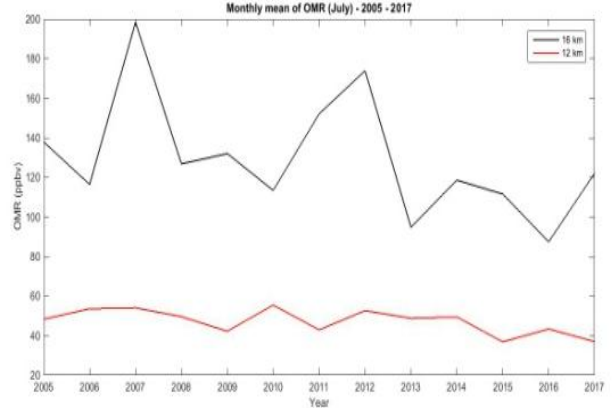

Figure 3 Plot of OMR variations with year for July monthly mean at $16 \mathrm{~km}$ and $20 \mathrm{~m}$ heights.

for unevenly spaced data, estimates the power spectrum based on least squares fit of sinusoidal waves [17]. LSP method has been applied to the fluctuations of OMR and temperature for the entire data range of 13 years, i.e., from 2005 to 2017, as this method is less sensitive to long gaps in the data and provides a reasonably good approximation to spectral power as a function of frequency [18]. The fluctuations of OMR and temperature have been butterworth low pass filtered for 24 months (2 years). Figure 4 shows time height distribution of power spectral density (PSD) of OMR and temperature. From the figure 4 (a) it can be observed that in the periodogram of temperature, higher period waves centered around 3 years dominate near tropopause region 14-16 km height. The waves with period in the range $3.5-4.5$ years are seen in the height range $16-21 \mathrm{~km}$ which influence trace gas constituents in lower stratosphere as this feature reflects in the contour plot of OMR in figure 2 (b). The figure 4 (b) shows the PSD of OMR against time and height. It can be observed from the figure that in troposphere between 6 - $8 \mathrm{~km}$ height waves of longer period of 2.5-3 years appear with maximum intensity. Near tropopause region of above $16 \mathrm{~km}$ height, oscillations of period with 3-4 years are prominantly seen and above $20 \mathrm{~km}$ height periods centered around 3 years dominate as shown from the figure 4(b).

The seasonal analysis of OMR in a year has been studied using wavelet transform in the present work. For this, we select a particular year where data is good without having

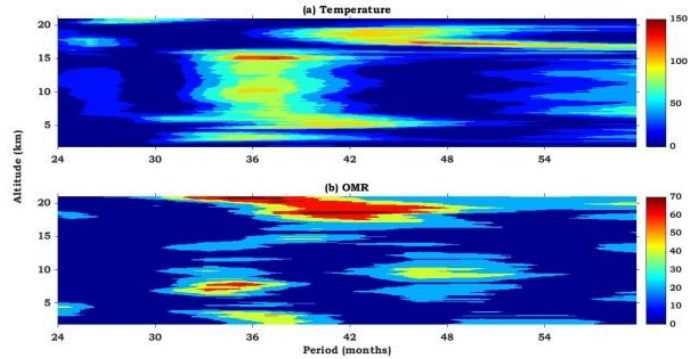

Figure 4 Lomb-Scargle Periodogram of time-height cross sections of power specrtal density (a) Temperature and

(b) OMR for the years 2005-2017

long and continuous data gaps. The fluctuations of OMR are subjected to Morlet wavelet transform. The year 2008 has been chosen for this purpose and figures 5 (a) and 5 (b) represent normalized spectral amplitudes that result from wavelet analysis of OMR in troposphere, by taking average height range of $8-16 \mathrm{~km}$ and in lower stratosphere with average of $16-21 \mathrm{~km}$ height, respectively.

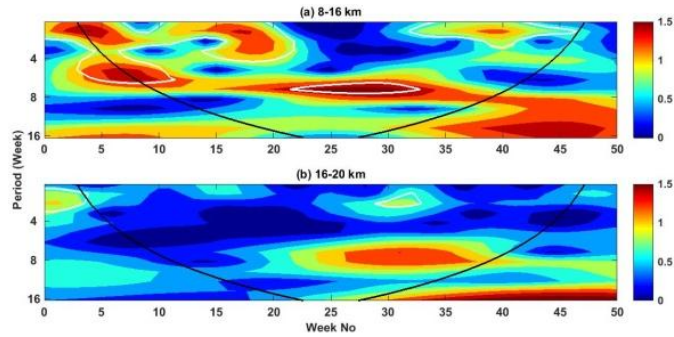

Figure 5 Wavelet analysis of normalized spectral amplitudes of OMR for the year 2008 in height regions (a) 8-16 km and (b) 16-20 km.

MJO oscillations of 50 - 60 days period dominate during summer months of 20 - 30 week number and lower period Kelvin waves of 14 - 20 days prominant during winter and spring months in troposphere, as indicated from the figure 5 (a). In stratosphere, MJO with 49 - 60 days (8 - 6 week) period appear with maximum amplitude during summer months which can be seen from the figure 5 (b).

Amplitude variation of MJO with period 55 - 60 days in a year, in troposphere and in lower strastosphere, are shown in figures 6 (a) and 6 (b). It can be seen from the figures that July month of summer season exhibits amplitude peak of $1.4 \mathrm{ppbv}$ in both troposphere and lower stratosphere regions. In stratosphere, while the width of the amplitude peak is narrow at July month, the amplitude exhibits a broad peak, extending from summer to fall months in troposphre region, as seen from the figures.

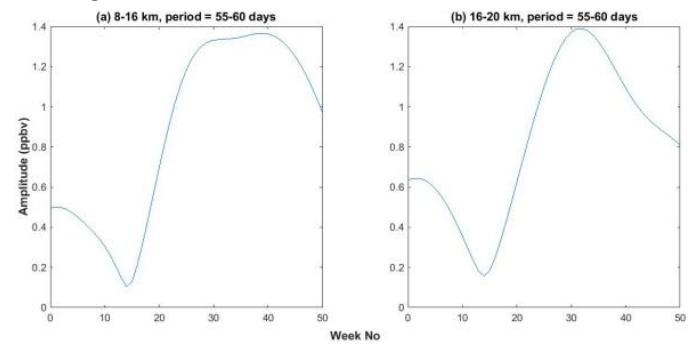

Figure 6 Plot of normalized spectral amplitudes of OMR with time from wavelet analysis for the year 2008 , for the period 55-60 days in height regions (a) 8-16 km and (b) $16-20 \mathrm{~km}$.

\section{CONCLUSIONS}

The analyses of seasonal, annual and interannual variabilities of OMR at Costa Rica have been studied from 2005 to 2017 years. The interannual variation of OMR was found to be maximum near tropopause region during summer. From periodogram analysis of OMR over the 13 years, QBO and even higher period oscillations dominate near tropopause and in lower stratosphre regions. It was concluded that large interannual perturbations of OMR were caused by QBO and higher period oscillations. The wavelet analysis revealed the presence of MJO waves near tropopause and lower stratosphere regions during summer months and lower period Kelvin waves during winter and spring seasons which might cause maximum seasonal variability.

Published By:

Blue Eyes Intelligence Engineering \& Sciences Publication

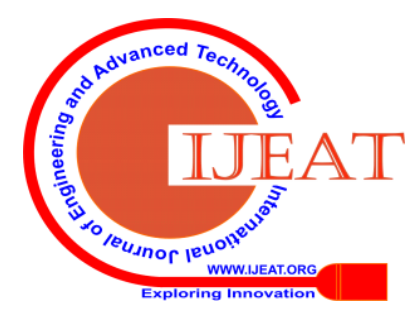




\section{ACKNOWLEDGEMENTS}

The authors acknowledge NASA for its project SHADOZ and co-investigators of Costa Rica station for radiosonde and Ozonesonde launches and making the data available to users. The authors are thankful to the management of the institute for their kind encouragement. The computations have been carried out in the lab developed by DST's FIST grant.

\section{REFERENCES}

1. Fujiwara, M., Kita, K., \& Ogawa, T, “ Stratosphere-troposphere exchange of ozone associated with the equatorial Kelvin wave as observed with ozonesondes and rawinsondes", Journal of Geophysical Research , 103, 1998, 19173-19182.

2. Fadnavis, S., Chakraborty, T., \& Beig, G, "Seasonal stratospheric intrusion of ozone in the upper troposphere over India", Annales Geophysicae , 28 (11), 2010,2149-2159.

3. Ghude, S., Kulkarni, S., Kulkarni, P., Kanawade, V., Fadnavis, S., Pokhrel, S., et al, "Anomalous low tropospheric column ozone over Eastern India during the severe drought event of monsoon 2002: a case study”,Environmental Science and Pollution Research , 18 (8), 2011,1442-1455.

4. Randel, W., Park, M., Emmons, L., Kinnison, D., Bernath, P., Walker, K.,et al, "Asian Monsoon Transport of Pollution to the Stratosphere”, Science, 328 (5978),2010, 611-613.

5. Randel, W., \& Thompson, A," Interannual variability and trends in tropical ozone derived from SAGE II satellite data and SHADOZ ozonesondes", Journal of Geophysical Research , 201,116.

6. Fadnavis, S., Dhomse, S., Ghude, S., Iyer, U., Buchunde, P., Sonbawne, S., et al.," Ozone trends in the vertical structure of Upper Troposphere and Lower stratosphere over the Indian monsoon region", International Journal of Environmental Science and Technology , 11 (2),2014, 529-542.

7. Logan, J., \& Kirchhoff, V," Seasonal variations of tropospheric ozone at Natal, Brazil", Journal of Geophysical Research , 91, 1986,7875-7881

8. Stolarski, R., Waugh, D., Wang, L., Oman, L., Douglass, A., \& Newman, P.," Seasonal Variation of Ozone in the Tropical Lower Stratosphere: Southern Tropics are Different from Northern Tropics", Journal of Geophysical Research , 119 (10), 2014,6196-6206.

9. Kumar, P., Dutta, G., Mohammad, S., \& Rao, B," Climatology of diurnal tide and its long-term variability in the lower middle atmosphere over a tropical station.",Theoretical and Applied Climatology , 130,2017, 151-162.

10. Liu, J., Rodriguez, J., Steenrod, S., Douglass, A., Logan, J., Olsen, M., et al.," Causes of interannual variability over the southern hemispheric tropospheric ozone maximum", Atmospheric Chemistry and Physics , 17 (5),2017, 3279-3299.

11. Rao, T., Arvelius, J., Kirkwood, S., \& Gathen, P, "Climatology of ozone in the troposphere and lower stratosphere over the European Arctic", Advances in Space Research , 34 (4), 2004,754-758.

12. Werner, R., Stebel, K., Hansen, H., Hoppe, U.-P., Gausa, M., Kivi, R., et al.," Study of the seasonal ozone variations at European high latitudes", Advances in Space Research , 47 (4), 2011, 740-747.

13. Schoeberl, M., Selkirk, H., Vömel, H., \& Douglass, A,"Sources of seasonal variability in tropical upper troposphere and lower stratosphere water vapor and ozone: Inferences from the Ticosonde data set at Costa Rica”, Journal of Geophysical Research , 120 (18), (2015, 9684-9701.

14. Selkirk H, Vömel H, Canossa J, Pfister L, Diaz J, Fernández W et al,’Detailed Structure of the Tropical Upper Troposphere and Lower Stratosphere as Revealed by Balloon Sonde Observations of Water Vapor, Ozone, Temperature, and Winds During the NASA TCSP and TC4 Campaigns", Journal of Geophysical Research , 2010, 115.

15. Fujiwara, M., Vömel, H., Hasebe, F., Shiotani, M., Ogino, S.-Y., Iwasaki, S., et al.,"Seasonal to Decadal Variations of Water Vapor in the Tropical Lower Stratosphere Observed with Balloon-Borne Cryogenic Frost Point Hygrometers", 2010, Journal of Geophysical Research , 115.

16. Pan, L., Paulik, L., Honomichl, S., Munchak, L., Bian, J., Selkirk, H., et al.,'Identification of the tropical tropopause transition layer using the ozone-water vapor relationship", Journal of Geophysical Research , 119 (6), 2014,3586-3599.
17. Scargle J," Studies in astronomical time series analysis. II - Statistical aspects of spectral analysis of unevenly spaced data", The Astrophysical Journal , 263, 1982, 835-853.

18. Press, W., Teukolsky, S., Vetterling, W., \& Flannery, B,” Numerical recipes in C (2nd ed.): the art of scientific computing",1992.

\section{AUTHORS PROFILE}

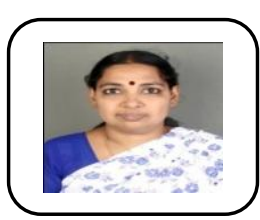

Dr. M. Kanaka Durga, working as Assoc. professor in Vig nana Bharathi Institute of Technology, Hyderabad, India. She did her M.Sc, $\mathrm{PhD}$ from Osmania University. Hyderabad. Her area of specialization is space physics.

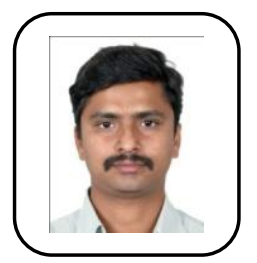

Dr. P. Vinay Kumar, working as Asst. professor in Aurora's Technological Research Institute, Hyderabad, India. He did his M.Sc from Osmania University, Hyderabad and $\mathrm{PhD}$ from Jawaharlal Nehru Technological Institute, Hyderabad.

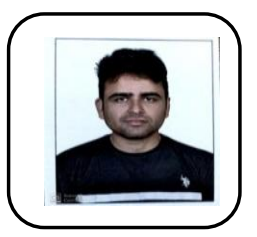

Dr. Mohammad Salauddin is working as post doctoral fellow in Academia Sinica, Taipei, Taiwan. He did his M.Sc from Osmania University, Hyderabad and $\mathrm{PhD}$ from Jawaharlal Nehru Technological Institute, Hyderabad.

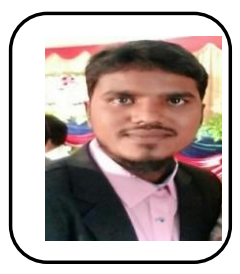

Mohammed Yousuf is a research scholar in Vignana Bharathi Institute of Technology, Hyderabad, India. He is working in ISRO RESPOND project. His area of interest is GPS/GNSS positioning. He has completed his B.Tech and M.Tech from Jawaharlal Nehru Technological Institute, Hyderabad and pursuing his PhD from Koneru Lakshmaiah University, Vijayawada, India.

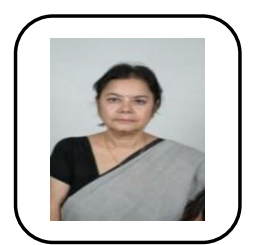

Dr. Gopa Dutta is a director of Research and Development center, Vignana Bharathi Institute of Technology, Hyderabad, India. She did her M.Sc from Jadhavpur University, Kolkata, West Bengal, India and $\mathrm{PhD}$ from Gujarat University, Gujarat, India. Her area of specialization is space physics.
Published By:

Blue Eyes Intelligence Engineering \& Sciences Publication (C) Copyright: All rights reserved.

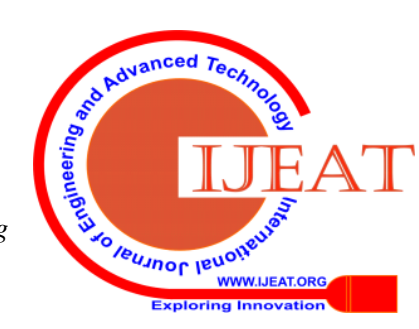

